\title{
Analisando as habilidades comunicacionais em uma criança com Transtorno do Espectro Autista participante de intervenções assistidas por animais
}

Edlene Alves de Souza ${ }^{1}$ Ivani Cristina Voos ${ }^{2}$

\begin{abstract}
Resumo:
A relação homem-animal existe desde os tempos mais remotos. Porém, apenas na idade contemporânea tornou-se fonte de pesquisas no âmbito da saúde, educação e psicologia. Assumindo a premissa mencionada, esta pesquisa tem como objetivo geral analisar como podem ser caracterizadas as habilidades comunicacionais de uma criança com Transtorno do Espectro Autista - TEA - a partir da participação em intervenções assistidas por animais. Os instrumentos de coleta de dados da pesquisa são: diários de bordo e videogravações das intervenções, que foram transcritas e, posteriormente, analisadas seguindo alguns princípios do estudo de caso. As intervenções aconteceram remotamente, pela plataforma Google Meet, devido às restrições impostas pela Covid-19 e ocorriam quinzenalmente, realizadas com o consentimento e acompanhamento da família. $O$ trabalho foi realizado numa instituição da rede federal de educação em parceria com o Corpo de Bombeiros de Santa Catarina e contou com a participação de seis pesquisadoras, uma criança com TEA e dois cães. Pudemos inferir que houve intenções linguísticas por parte da criança, entretanto, é importante destacar que elas foram analisadas com parcimônia, dado o contexto vivenciado.
\end{abstract}

\section{Palavras-chave:}

Terapia assistida por animais. Transtorno do Espectro Autista. Habilidades comunicacionais.

\section{Analyzing communication skills in a child with Autistic Spectrum Disorder participating in animal-assisted interventions}

\begin{abstract}
:
The human-animal relationship has existed since ancient times. However, only in the contemporary age it became the source of several researches in the fields of health, education, and psychology. Assuming the premise mentioned above, this research has as a general objective: to analyze how the communication skills of a child with Autistic Spectrum Disorder - ASD - can be characterized from
\end{abstract}

1 Licenciada em Pedagogia Bilíngue-IFSC. E-mail: limaedlene12@gmail.com. ORCID iD: https://orcid.org/0000-0001-8341-4265. 2 Doutora em Educação Científica e Tecnológica - UFSC. Departamento de Ensino, Pesquisa e Extensão do Instituto Federal de Santa Catarina - Campus Palhoça. E-mail: ivani.voos@ifsc.edu.br. ORCID iD: https://orcid.org/0000-0001-7444-506X . 
the participation in Animal-Assisted Interventions. The data collection instruments of the research are: on-board diaries and videotapes of the interventions performed with the child, which were transcribed and later analyzed following some principles of the case study. The interventions took place remotely, through the Google Meet platform, due to the restrictions imposed by Covid-19, and occurred every two weeks, with the consent and monitoring of the family. The work was carried out in an institution of the federal network in partnership with the Fire Department of Santa Catarina and counted on the participation of six researchers, one child with ASD, and two dogs. Thus, in the interventions we could infer that there were linguistic intentions by the child, however, it is important to emphasize that they should be analyzed sparingly given the context experienced.

\section{Keywords:}

Animal assisted therapy. Autistic Spectrum Disorder. Communication skills.

\section{Analizar las habilidades comunicacionales en un niño con trastorno del espectro autista participante en intervenciones asistidas por animales}

\section{Resumen:}

La relación hombre-animal existe desde los tiempos más remotos. Sin embargo, solo en la edad contemporánea se convirtió en fuente de investigaciones en el ámbito de la salud, educación y psicología. Asumiendo la premisa mencionada esta investigación tiene como objetivo general: analizar cómo pueden ser caracterizadas las habilidades comunicacionales de un niño con Trastorno del Espectro Autista - TEA - a partir de la participación en Intervenciones Asistida por Animales. Los instrumentos de recolección de datos de la investigación son: diarios de a bordo y videograbaciones de las intervenciones fueron transcritas y, posteriormente, analizadas siguiendo algunos principios del estudio de caso. Las intervenciones ocurrieron remotamente, por la plataforma Google Meet, debido a las restricciones impuestas por Covid-19 y ocurrían quincenalmente, realizados con el consentimiento y acompañamiento de la familia. El trabajo fue realizado en una institución de la red federal de Educación en colaboración con el Cuerpo de Bomberos de Santa Catarina y contó con la participación de seis investigadoras, un niño con TEA y dos perros. Podríamos inferir que hubo intenciones lingüísticas por parte del niño, sin embargo, es importante destacar que las mismas sean analizadas con parsimonia dado el contexto experimentado.

Palabras clave:

Terapia asistida por animales. Trastorno del Espectro Autista. Habilidades de comunicación.

\section{Introdução}

Ao longo de muitos anos na história, encontram-se registros de que as pessoas com deficiências foram tratadas e compreendidas como incapazes, e tal fato culmina com o estabelecimento de espaços educativos e sociais segregados, instalando processos de exclusão/segregação (BRASIL, 2001; CAPOTE, 2009; JANUZZI, 2012). Porém, a evolução nos movimentos sociais coordenados por grupos de pessoas com deficiência no mundo trouxe novas abordagens e formas diferenciadas de entendermos os processos de inclusão. Falamos aqui do modelo social da deficiência, o qual contribui de maneira significativa para que a deficiência seja compreendida para além das 
limitações do corpo, mas também como resultado de fatores sociais e ambientais, contrapondo o modelo médico (DINIZ, 2007).

No Brasil, a Constituição Federal de 1988 assumiu o compromisso com o princípio da igualdade, inclusive para escolarização de todos, independentemente da origem, raça, do sexo, da cor e idade (BRASIL, 1988). A partir desta data, o País assina e ratifica inúmeros documentos e tratados internacionais (Tailândia, 1990, Espanha, 1994, Guatemala, 1999, ONU, 2007). Dentre as diretrizes e os princípios que apresentam os documentos supracitados, a sociedade e as escolas do mundo todo são conclamadas a combater atitudes discriminatórias, possibilitando o acolhimento de todas as crianças, independentemente de suas condições físicas, intelectuais, emocionais, linguísticas, entre outras (BRASIL, 1994).

Tais marcos, histórico e legislativo, fomentaram a criação de políticas públicas no âmbito/ perspectiva da educação inclusiva. No Brasil, de modo mais imperativo, tal perspectiva parece tomar corpo no ano de 2008, quando é assinada a Política Nacional de Educação Especial na Perspectiva da Educação Inclusiva (BRASIL, 2008). Documento relevante que aborda o papel da escola e da sociedade na superação de práticas excludentes e direcionando a educação especial e suas ações para o atendimento às especificidades dos estudantes numa perspectiva denominada de inclusiva e não mais paralela (BRASIL, 2008).

Consequentemente, consolidando as políticas públicas brasileiras atentas a uma perspectiva de educação inclusiva, é criada a Política de Proteção dos Direitos da Pessoa com Transtorno do Espectro Autista (TEA), Lei no 12.764 (BRASIL, 2012).

Analisando os variados documentos legislativos e suas indicações, bem como o diálogo acerca dos métodos, das técnicas, metodologias e estratégias que são objetos de pesquisas no intuito de possibilitar a participação ativa de pessoas com deficiências, não somente nas escolas, mas em outros ambientes sociais, elaboramos as práticas que serão, posteriormente, apresentadas.

Partindo dos pressupostos elencados, trazemos a este trabalho uma discussão ainda incipiente em nosso país ${ }^{3}$, mas que julgamos de extrema necessidade: podem as Intervenções Assistidas por Animais (IAAs) serem classificadas como um serviço de tecnologia assistiva ${ }^{4}$ ? O uso da tecnologia assistiva vem sendo apresentado nas pesquisas em duas frentes, a saber, os recursos e os serviços. Ambos são considerados salutares para a participação equitativa das pessoas com deficiências em diversas atividades (BRASIL, 2009). Na busca de lançar problematizações iniciais a essa incipiente discussão, é relevante dizer que a tecnologia assistiva é uma área ampla que envolve múltiplos conhecimentos que não podem ser reduzidos apenas a máquinas ou equipamentos. Tal aspecto leva-nos a qualificar o recurso animal, sobretudo os cães, no processo de desenvolvimento de crianças sem oralidade com Transtorno do Espectro Autista como sendo um serviço da tecnologia assistiva.

É importante destacar que, em geral, as crianças com TEA, podem apresentar uma gama de dificuldades neurológicas classificadas no espectro desde os níveis mais leves aos níveis mais profundos; tais questões podem sinalizar possíveis barreiras para a participação em atividades educacionais, lúdicas e ou cotidianas. Dentre as barreiras, destacam-se: as dificuldades comportamentais, interacionais e dificuldades comunicacionais. Sendo assim, entendemos que tanto os recursos quanto os serviços de tecnologia assistiva podem contribuir para o desenvolvimento infantil de crianças com TEA. Por isso, aqui propomos a referida discussão e a consequente classificação/qualificação das IAAs como um serviço de tecnologia assistiva, que, se assim considerado, pode vir a ser implementado em espaços escolares e/ou terapêuticos, de modo público e gratuito,

\footnotetext{
3 Nas revisões de literatura realizadas para essa pesquisa, conforme mencionado no texto, não foram localizadas discussões com esse viés. Apenas um Projeto de Lei da Assembleia Legislativa do Rio de Janeiro (PL 512/2019) faz menção a essa caracterização, mas não encontramos a aprovação do PL. No âmbito nacional, não localizamos.

4 No Brasil, a área de TA está definida pelo CAT - Comitê de Ajudas Técnicas como "[...] uma área do conhecimento, de característica interdisciplinar, que engloba produtos, recursos, metodologias, estratégias, práticas e serviços que objetivam promover a funcionalidade, relacionada à atividade e participação, de pessoas com deficiência, incapacidades ou mobilidade reduzida, visando sua autonomia, independência, qualidade de vida e inclusão social" (BRASIL, 2009, p. 13).
} 
podendo contribuir significativamente no enfrentamento de barreiras que se impõem às pessoas que vivem a condição humana do TEA.

A Terapia Assistida por Animais - TAA $^{5}$ - representa algo inovador e pode promover mudanças nas questões intelectuais, motoras e comunicacionais; já há indícios de que a interação homem-animal aponta melhorias na cognição, fala, socialização, autoestima e desenvolvimento físico (MARINHO; ZAMO, 2017).

Contudo, a pesquisa tem como objetivo geral analisar como podem ser caracterizadas as habilidades comunicacionais de uma criança com Transtorno do Espectro Autista a partir da participação em Intervenções Assistidas por Animais.

Durante a pesquisa e nas buscas realizadas em bases de dados, foi possível averiguar que tal temática é pouco pesquisada em nosso país, o que pode sinalizar a necessidade de um maior investimento e desenvolvimento na área, trazendo contribuições para a oferta desse serviço às pessoas que dele necessitem. Foram realizadas buscas nas plataformas PubMed, que compreende pesquisas no campo da biomedicina e da saúde, e SciElo Brasil, com os seguintes descritores: Terapia Assistida por Animais, Transtorno do Espectro Autista e Comunicação. Utilizamos o período correspondente entre os anos de 2010 a 2020, pensando em estabelecer um período referente à última década de pesquisas desenvolvidas no país acerca da temática. $\mathrm{O}$ que podemos perceber de imediato na busca realizada é um número reduzido de trabalhos.

\section{Intervenções assistidas por animais: um pouco da história e do conceito}

Gonçalves e Gomes (2017) explicam que o uso de animais em terapias teve origem na Alemanha, em 1792, em uma instituição situada em Retiro Yorke, especializada em tratamentos de pessoas com transtornos mentais. Anos mais tarde, em 1942, os benefícios desse tratamento foram reconhecidos, passando a ser utilizado em pacientes com Mal de Alzheimer, autistas, vítimas de abusos sexuais, desordem mental e emocional.

Nogueira et al. (2019) apontam que a Pet Terapia foi criada entre os anos de 1970 e 1980, e consistia no uso de animais, porém o termo não traduzia as possibilidades de trabalho com os animais. Assim, foi substituído por Atividades Assistidas por Animais (AAA) e Terapia Assistida por Animais (TAA). A fim de evitar confusões pelos diversos termos utilizados anteriormente como, pet terapia, zooterapia, a Delta Society (órgão que regulamenta os programas com animais nos Estados Unidos) dividiu os termos em dois grupos: Atividades Assistidas por Animais (AAA) e Terapia Assistida por Animais (TAA). O primeiro consiste em atividades de entretenimento e recreação, com o objetivo de melhoria na qualidade de vida, sem critérios definidos. O segundo termo trata de uma intervenção direcionada, com critérios e objetivos claros e específicos. Tem o objetivo de melhorar aspectos sociais, físicos, emocionais e cognitivos das pessoas é um processo terapêutico no qual o animal é parte integrante do processo de tratamento.

Outra importante associação internacional que trata acerca do assunto é a International Association of Human-Animal Interaction Organizations (IAHAIO). No documento intitulado As definições da IAHAIO para as Intervenções Assistidas por Animais e as diretrizes para o bem-estar dos animais envolvidos nas Intervenções Assistidas com Animais, define-se que as IAA são intervenções formais, estruturadas, com objetivos definidos que incluem a presença e participação de animais e aplicada por profissionais da área da saúde, educação e da área social, com a finalidade de promover benefícios terapêuticos para as pessoas (IAHAIO, 2018). Esclarece ainda que existem

5 A Terapia Assistida por Animais (TAA) é uma intervenção terapêutica planejada, estruturada, com objetivos definidos e dirigidos por profissionais da saúde, da educação e do âmbito social. Tem como objetivo o desenvolvimento físico, cognitivo e socioemocional de forma grupal ou individual (IAHAIO - International Association of Human-Animal Organizations, 2018). 
três distintas modalidades, a saber: a Terapia Assistida por Animais - TAA -, a Atividade Assistida por Animais - AAA - e, por fim, a Educação Assistida por Animais - EAA.

A fim de elucidar sobre as três formas distintas, o documento explica que a Terapia Assistida com Animais é uma intervenção planejada, estruturada, com metas definidas que envolve a participação ativa de animais, conduzida por profissionais da saúde, educação e âmbito social devidamente habilitados. O processo é documentado e avaliado. Seu objetivo é promover o desenvolvimento físico, cognitivo e socioemocional. Já as Atividades Assistidas com Animais, são interações informais, realizadas com a presença de animais para fins motivacionais, educativos e recreativos. Não possuem foco terapêutico. São realizadas por um profissional da educação, da saúde ou da área social, podendo, por exemplo, ser realizadas com visitas a centros geriátricos. Por fim, mas não menos importante, define Educação Assistida por Animais como uma intervenção com metas definidas, planejadas e estruturadas. São mantidas por profissionais da educação qualificados, geralmente conduzidas por professores da educação especial, com foco no desenvolvimento de habilidades cognitivas e sociais.

Embora pareça ser difícil separar as três formas de atuação das Intervenções Assistidas por Animais, por apresentarem similaridades, é muito mais comum encontrar na literatura referências à Terapia Assistida por Animais, classificada como uma forma de trabalho alternativo, utilizada por profissionais para promover a saúde de crianças, jovens e adultos (HACK; SANTOS, 2017). Os autores explicam que o cão se tornou especial em razão da sua capacidade de transmitir alegria e cativar os indivíduos. "O cão é visto como coterapeuta e um auxílio junto aos profissionais em atividades de ensino, estimulação e reabilitação" (HACK; SANTOS, 2017, p. 153). Ele é muito útil nas intervenções, auxiliando no desenvolvimento da afetividade e da formação de vínculos.

Para Carvalho (2014), o contato dos animais com as crianças, sobretudo os cães, introduz uma comunicação recíproca que proporciona o desenvolvimento da autoestima, do respeito e companheirismo. Gonçalves e Gomes (2017) apontam que a TAA pode ser um recurso muito rico para o auxílio de profissionais como: psicólogos, pedagogos, médicos, enfermeiros, fisioterapeutas, fonoaudiólogos, dentre outros; porém, ainda é pouco conhecida e não é facilmente encontrada de forma gratuita. Vale ressaltar que essa modalidade de terapia não substitui outras, como fisioterapia, tratamento psiquiátrico, terapia ocupacional etc., contudo, ela possui cunho complementar e inovador.

Os cães, segundo Gonçalves e Gomes (2017), são a espécie mais utilizada na Terapia Assistida com Animais e algumas pesquisas apontam para o aumento da capacidade de concentração, aumento da consciência social e das habilidades comunicativas na criança.

\section{Conversando um pouco sobre o Transtorno do Espectro Autista - TEA - e as habilidades comunicacionais}

O Transtorno do Espectro Autista (TEA) é um transtorno do neurodesenvolvimento, mental ou comportamental, que pode ou não apresentar comprometimento intelectual e na linguagem (DSM-5, 2014). Neste trabalho, embora apresentemos os aspectos clínicos do TEA, nós o compreendemos e nos afiliamos à ideia de TEA como características humanas. 
Conforme a quinta edição do Manual Diagnóstico e Estatístico de Transtornos Mentais (DSM-5, 2014) ${ }^{6}$, o TEA se caracteriza por dificuldades persistentes em múltiplos contextos, tais como a comunicação social e as interações sociais. Registra a presença de padrões restritos e repetitivos de comportamentos, interesses ou atividades. O diagnóstico tem características clínicas individuais por meio de especificadores com ou sem aspectos relacionados à deficiência intelectual concomitante, comprometendo ou não a linguagem. É sobre este último aspecto que dirigimos nosso olhar no texto, já que a criança participante da pesquisa se caracteriza como uma criança que não oraliza e com diagnóstico de TEA.

As dificuldades na comunicação oral podem ser percebidas na interação social, já que podem incluir dificuldades na linguagem e fala. Entretanto, é importante salientar que a ausência da fala oral não implica nem significa ausência de comunicação. É salutar entender que cada criança tem seu tempo para comunicar e expressar desejos, vontades e pensamentos que nem sempre serão expressas através da voz humana (AVILA, 2016).

Afinal o que significa comunicar? A expressão não está diretamente ligada à fala ou exclusivamente ligada à voz. Embora todos os pais esperem ouvir a voz do filho, é importante compreender que algumas crianças, mesmo quando expostas a ambientes linguísticos muito favoráveis, não irão desenvolver essa função como habitualmente acontece, mas se comunicarão de outros modos, a saber: gestos, expressões faciais, movimentos corporais, balbucios, olhares, choro, sorrisos, entre outros. Avila (2016) explica que não há nem podemos interpretar tais formas de comunicação como desfavoráveis ou com status menos importantes do que a voz.

Outro aspecto de extrema relevância que envolve a comunicação humana é a possibilidade da articulação de interações sociais. O estabelecimento de momentos dialógicos entre os sujeitos é considerado uma função primária dos seres humanos, em especial, porque geralmente a criança utiliza desse momento de interação social para comunicar algo, portanto, a ausência da fala (voz) pode ser interpretada como barreira nesse processo. Por esse motivo, a comunicação não oral, como mencionada, é tão relevante.

Segundo o DSM-5 (2014), o TEA pode estar fortemente associado ao transtorno da linguagem em termos de transtornos da aprendizagem (leitura, escrita e aritmética). Assim, sinalizamos que as dificuldades na comunicação mencionadas anteriormente podem sim trazer barreiras no compartilhamento do sistema linguístico, sobretudo quando a criança não consegue desenvolver a fala oral (DELIBERATO, 2015).

\section{Metodologia: um caminho percorrido}

É uma pesquisa de natureza qualitativa, descritiva que traz em sua constituição princípios do estudo de caso. A pesquisa qualitativa pode ter variados conceitos, tendo o ambiente como fonte natural de dados e o pesquisador como principal instrumento. André e Ludke (1986, p. 11) apontam que "A pesquisa qualitativa supõe o contato direto e prolongado do pesquisador com o ambiente e a situação que está sendo investigada". Há uma relação direta entre pesquisador e o ambiente de investigação, possibilitando situações diversificadas para implementar a pesquisa.

\footnotetext{
6 Importante destacar que, embora o texto apresente vários conceitos cunhados no modelo médico, e que, em um longo trecho se detém a explicar as características do TEA sob a ótica de documentos como o DSM-5 e outros, e por isso faz uso de expressões que são consideradas alinhadas ao referido modelo, nosso objetivo foi explicar ao leitor características humanas que se fazem presentes na vida da pessoa com TEA, sem, portanto, desejar ênfase na concepção do modelo médico. Ainda que reconheçamos que desde o século XVIII as discussões acerca da deficiência centralizaram-se neste modelo e parecem perdurar até hoje. Contrariamente, nós nos afiliamos às ideias do Modelo Social e salientamos que toda interpretação que vier a ser dada sobre o assunto deve ser à luz desse modelo, rompendo a concepção de correção dos déficits humanos (mesmo utilizando a expressão) e da existência de padrões de normalidade. O Modelo Social, já nos anos de 1960, no Reino Unido, com os estudos de Paul Hunt, contribuíram para uma nova concepção e aponta barreiras sociais e políticas que oprimem e segregam pessoas com deficiências na sociedade (DINIZ, 2007).
} 
Segundo as autoras André e Ludke (1986), é também considerada descritiva por apresentar entre outros aspectos: descrições de pessoas, acontecimentos, situações, transcrições de entrevistas e vídeos. Faz-se ainda uso de citações para esclarecer pontos de vista ou corroborar com afirmações.

A pesquisa foi submetida e aprovada pelo Comitê de Ética, sob Parecer Consubstanciado número 4.626.894. Como instrumento de análise, utilizamos alguns princípios do estudo de caso, o qual tem sido aplicado cada vez mais para a produção do conhecimento científico. Peres e Santos (2005) afirmam que o estudo de caso permite analisar um grupo específico e fazer relações entre a literatura e as experiências empíricas.

O pesquisador, portanto, eventualmente ver-se-á frente à necessidade de integrar dados de diferentes ordens - sejam eles sociais, biológicos, psicológicos, culturais, econômicos ou de qualquer outro tipo -, com o intuito de não perder de vista a multidimensionalidade de seu caso (PERES; SANTOS, 2005, p. 114).

André e Ludke (1986) complementam explicando que a pesquisa do tipo estudo de caso delimita o campo de pesquisa a algo simples ou complexo em um contexto, relacionando características distintas e particulares, ou até mesmo pode relatar semelhanças com outros casos e situações. Assim como deve elencar aspectos fundamentais como a descoberta, a interpretação em um contexto, a retratação da realidade de forma complexa e profunda, utilização de variadas fontes de informações e apresentação de diferentes pontos de vistas com uma linguagem mais acessível.

A fim de seguir os aspectos fundamentais do estudo de caso, foram utilizados dois instrumentos de coleta de dados, a saber, as videogravações das sessões de Intervenção Assistida por Animais com uma criança com TEA e o diário de bordo das sessões. Estes eram registrados sempre ao final da sessão e posteriormente comparados e analisados junto aos vídeos.

As intervenções foram videogravadas e posteriormente transcritas. Os estudos de Loizos (2008, p. 148) explicam que "O vídeo tem uma função óbvia de registro de dados sempre que algum conjunto de ações humanas é complexo e difícil de ser descrito compreensivamente por um único observador". Portanto, a videogravação é um instrumento que possibilita a construção de registros confiáveis e materiais empíricos válidos, diante das ações humanas complexas. Partindo desse pressuposto, Duarte, Eizenberg e Garcez (2011) afirmam que a videogravação é um importante instrumento de pesquisas com crianças, pois auxiliam no registro de detalhes que possam passar despercebidos pelo pesquisador, bem como manter-se fiel à linguagem gestual ou oral expressa no vídeo. Por isso, as videogravações apresentaram-se como relevantes na pesquisa.

Por fim, apresentamos aqui, de modo breve, os diários de bordo, instrumento utilizado com o objetivo de registrar e posteriormente permitir a reflexão sobre as anotações, especialmente, quando contrapostas ou complementares às videogravações. Segundo Zabalza (2004), os diários podem variar de acordo com os processos de coleta, conteúdos, periodicidades e avaliação das informações. São nomeados pelo tipo de narrativa utilizada, e, nesta pesquisa, escolhemos os diários analíticos, descritos como sendo um "[...] tipo de diário onde o observador se fixa nos aspectos específicos e/ou nas diversas dimensões que fazem parte da coisa que se deseja observar" (ZABALZA, 2004. p. 15). Os diários são recursos valiosos configurando-se ainda como um instrumento de pesquisa que permite refletir sobre o que se escreve, analisar a evolução dos fatos no decorrer do tempo e fomentar novos olhares para o objeto de estudo.

Para esta pesquisa, apresentamos a descrição de 1 (um) dos diários de bordo e a sua respectiva videogravação que, juntos, compõem o corpus analítico. 


\section{Apresentando as características da criança participante}

Esta pesquisa contou com a participação de 1 (uma) criança com 6 (seis) anos, do sexo masculino. Nomeado por Rubi a fim de manter em sigilo o seu verdadeiro nome, de acordo com o previsto no Termo de Consentimento Livre e Esclarecido assinado pelos responsáveis antes do início das atividades.

Rubi é uma criança diagnosticada com características do Transtorno do Espectro Autista, ouvinte, que não oraliza, até o presente momento.

Demonstra grande interesse pela música, característica que foi fortemente influenciadora dos planejamentos ao longo das intervenções. Sempre esteve acompanhado da mãe nas atividades, mora com a família, composta por pai, mãe e um irmão mais velho. Estudante de escola pública na rede regular de ensino, Rubi participa de outras terapias, as quais foram relatadas pela mãe (musicoterapia, fisioterapia e fonoterapia).

É importante ressaltar que Rubi já apresentava, no início das sessões, uma comunicação não oral, como puxar a mãe quando queria algo, dar sorrisos que sinalizavam que queria ou aceitava algo, assim como choros quando estava incomodado ou queria se retirar do espaço (no caso, queria sair da sala da casa, local onde a mãe participava com ele das atividades).

\section{Apresentando os cães participantes da pesquisa}

Marley (cão da corporação), raça Labrador Retriever, tem três anos de idade, é treinado e certificado para busca e resgate. Atua no grupamento do CBMSC sob a tutoria do soldado que o acompanha no projeto. O cão goza de excelente saúde física e mental e é acompanhado por veterinários da corporação. Sua participação, no período analisado, se deu através de videogravação, com comandos mediados pelo tutor, em contexto com as propostas de intervenção.

Maya, raça Golden Retriever, tem 1 (um) ano e meio de idade, está em treinamento, só participa das atividades a distância, sem contato físico com o participante. A cadela está em treinamento com base nos princípios do adestramento positivo, ainda não se encontra apta (conforme orientações internacionais IAHAIO) e educada para atividades na interação cães-humanos. Também goza de excelente saúde e é acompanhada por veterinária. Participou dos encontros, sempre sob a supervisão da tutora, professora responsável pelo projeto.

\section{Apresentando o contexto e o processo de construção da pesquisa}

Antes do início das atividades, foi realizada pela orientadora da pesquisa uma entrevista de acolhimento com a família e com a criança, em horário e dia previamente agendados. A entrevista ocorreu pela plataforma Google Meet, com o objetivo de levantar informações iniciais e de conhecer o histórico familiar e de saúde da criança (quais os gostos da criança, comunicação estabelecida com a família e se a criança apresenta medo de animais foram algumas das perguntas realizadas na entrevista). Após a entrevista, foi possível perceber que a família não deixou claro como se dava o processo de comunicação da criança e os familiares.

Segundo André e Ludke (1986), as informações obtidas durante a entrevista são tão importantes que precisam ser considerados critérios como respeito, sigilo e anonimato das informações adquiridas. Durante a entrevista, a família recebeu o Termo de Consentimento Livre e Esclarecido

- TCLE -, documento no qual a família toma ciência dos detalhes da pesquisa e autoriza a participação da criança, em conformidade com regras e legislação vigente de participação em pesquisa científica envolvendo pessoas para o andamento das atividades. 
Após os aceites firmados, o atendimento foi conduzido por um grupo de cinco estudantes de um curso de Licenciatura de uma instituição da rede federal de educação profissional e tecnológica, sob supervisão da professora orientadora. Todas as pesquisadoras atuam com trabalhos de pesquisa no Laboratório de Tecnologia Assistiva da instituição - LABTA ${ }^{7}$. As práticas realizadas tomaram os cuidados recomendados pela Organização Mundial de Saúde - OMS -, com distanciamento e isolamento social e, portanto foram realizadas de modo não presencial, utilizando a plataforma Google Meet, ocorriam quinzenalmente e tinham duração de trinta minutos. O trabalho contou com a parceria do Corpo de Bombeiros e com dois cães, os quais foram apresentados anteriormente.

Os interesses pessoais da criança, apresentados pela mãe na entrevista de acolhimento, subsidiaram parte das práticas realizadas, sendo que o interesse musical de Rubi foi fundamental para a participação e construção do vínculo da criança com a equipe. O grupo de pesquisadoras optou por intervenções lúdicas que envolvessem música, brinquedos, objetos e a participação dos cães, que ocorriam por meio de vídeos com atividades realizadas pelo cão, que eram enviados antes das intervenções ou apresentados à criança no momento da sessão.

A pesquisa acontece desde o ano de 2019 e ainda se mantém realizando encontros quinzenais. Porém, nesta pesquisa, daremos ênfase exclusiva ao período do segundo semestre do ano de 2020. Nesse período, foram realizados 8 (oito) encontros, e, para este momento, selecionamos 1 (um), devido ao espaço no texto. O encontro selecionado ocorreu no dia quinze de dezembro de 2020, e será descrito a seguir, apresentado e analisado.

Nesse dia, a intervenção foi mediada por duas pesquisadoras do grupo e a professora orientadora da pesquisa. Rubi estava acompanhado da mãe, e se mostrou concentrado. Sentado ao lado da mãe, ele demonstra prestar atenção ao que se passa na tela do computador. Um cachorro de brinquedo foi apresentado, a pesquisadora faz o som de um latido de cão (au au au) e pede para Rubi repetir o som que o cachorro faz. Ele observou, emitiu balbucios, mexeu as mãos, fato bastante interessante, que possibilitou inferir que a criança de fato apresentou intenção linguística para com as pesquisadoras. Um carrinho de brinquedo foi apresentado e Rubi chega perto da tela e mais uma vez parece observar. De imediato, as pesquisadoras percebem que Rubi tem um carrinho de brinquedo também, o qual está na sala aparente no vídeo, então, a pesquisadora solicita a Rubi que mostre o carrinho - a mãe o auxiliou na tarefa. Como é possível observar na videogravação realizada nesse dia e posteriormente também registrado no diário de bordo, Rubi não demonstra interesse em pegar o objeto sozinho.

A criança é convidada para ouvir a música Dirigindo meu carro, que é tocada no violão, que objetiva o trabalho com os sons do carro. Foram trabalhados os seguintes sons: bi bi bi, brum brum, xi xi xi, entre outros. Rubi sorriu, movimentando as mãos durante a execução da música. Em outro momento, a música é modificada e o som do latido do cão, feito pela pesquisadora, é introduzido. Logo na sequência, a pesquisadora que toca o violão cessa a música e solicita para Rubi repetir a expressão "au, au, au" enquanto todos os participantes fazem o movimento com a boca imitando o latido do cão.

Rubi demora alguns minutos e parece repetir o movimento bucal realizado, parece uma tentativa de repetir o latido do cachorro, abre a boca imitando a ação ensinada pelas pesquisadoras. A intervenção encaminha-se para o final, a professora orientadora abre a câmera mostrando a cadela Maya (cadela participante do projeto), convidando Rubi para vê-la, ele sorriu e se aproximou da tela. O grupo despediu-se do Rubi, dando tchau e desligando as câmeras, ação necessária para que ele compreenda que a sessão está sendo encerrada.

7 O Laboratório de Tecnologia Assistiva (Labta), do Instituto Federal de Santa Catarina (IFSC), foi criado em 2018 . O laboratório conta com um professor Licenciado em Educação Especial, bolsistas e estagiários, que trabalham de forma conjunta para a proposição de estratégias, recursos, materiais pedagógicos acessíveis e para a oferta do serviço de AEE. Tem o objetivo de minimizar as barreiras vivenciadas por alunos da Educação Especial e configura-se ainda, um espaço de formação para servidores do IFSC, estudantes em processo de formação inicial e professores das redes municipal e estadual. (Jornalismo IFSC). 


\section{Uma análise ainda preliminar das intervenções assistidas por animais e uma criança com Transtorno do Espectro Autista}

A partir desse momento, nós nos propomos a estabelecer uma análise, ainda que inicial, importante, das interações e intenções linguísticas estabelecidas por Rubi no que tange à sessão apresentada, sem pretensão de esgotar as discussões e com a parcimônia que o momento e o contexto exigem. Apresentaremos a seguir a análise do episódio selecionado e descrito em que as intenções linguísticas da criança parecem presentes de modo significativo.

Em todos os encontros, o grupo de pesquisadoras procurou estimular o desenvolvimento da linguagem por meio de brinquedos, da música e da presença virtual do cão, sempre procurando fazer com que a criança emitisse sons ou imitasse algo. Foram propostas nas atividades desenvolvidas estratégias diversificadas, como na atividade descrita no diário de bordo, fazer os sons do carro e do latido do cão. Tais práticas eram desenvolvidas a fim de perceber habilidades linguísticas da criança sejam por meio de gestos, movimentos, balbucios, entre outros.

Deliberato (2015) explica que, ao fazer uso de diferentes recursos e estratégias da área da comunicação, alunos que não conseguem desenvolver a fala podem aprender a expressar sentimentos, vontades e ideias por meio de outras habilidades (expressões faciais, gestos e linguagem corporal). Assim, com base nas impressões descritas nos diários de bordo, nas análises realizadas das videogravações transcritas e nos estudos de Sant’Anna (2015), elaboramos um quadro que apresenta habilidades comunicacionais percebidas na criança no episódio analisado.

Quadro 1: Habilidades comunicacionais na IAA

\begin{tabular}{|c|c|c|c|c|c|c|}
\hline \multirow[b]{2}{*}{ Data } & \multirow[b]{2}{*}{ Intervenção } & \multicolumn{4}{|c|}{ COMUNICAÇÃO NÃO ORAL } & \multirow{2}{*}{$\begin{array}{c}\text { COMUNICAÇÃO } \\
\text { ORAL } \\
\text { Sons } \\
\text { Palavras } \\
\text { Balbucio }\end{array}$} \\
\hline & & $\begin{array}{l}\text { Interesses } \\
\text { lúdicos }\end{array}$ & $\begin{array}{c}\text { Imitações } \\
\text { Gestos }\end{array}$ & $\begin{array}{c}\text { Expressão } \\
\text { do rosto } \\
\text { sentimentos }\end{array}$ & $\begin{array}{l}\text { Ação em } \\
\text { relação aos } \\
\text { objetos e } \\
\text { música }\end{array}$ & \\
\hline $15 / 12$ & $\begin{array}{l}\text { Atividade } \\
\text { musical } \\
\text { com objetos: } \\
\text { carrinho, } \\
\text { cachorro de } \\
\text { pelúcia. } \\
\text { violão. } \\
\text { cão Maya; }\end{array}$ & $\begin{array}{l}\text { Atentou-se aos } \\
\text { brinquedos: } \\
\text { carrinho e } \\
\text { cachorro de } \\
\text { pelúcia; } \\
\text { Observou o } \\
\text { carrinho na tela } \\
\text { e olhou para o } \\
\text { carrinho dele; }\end{array}$ & $\begin{array}{c}\text { Tentou } \\
\text { imitar o } \\
\text { latido do } \\
\text { cão, ação } \\
\text { motora } \\
\text { não } \\
\text { vocálica; } \\
\text { Abriu } \\
\text { a boca; }\end{array}$ & Sorriu; & $\begin{array}{l}\text { Aproximou- } \\
\text { se da tela } \\
\text { para ver a } \\
\text { Maya; } \\
\text { Balançou as } \\
\text { mãos pare- } \\
\text { cendo estar } \\
\text { feliz; }\end{array}$ & $\begin{array}{l}\text { Emitiu som com a } \\
\text { vocalização } \\
\text { "hum, hum" } \\
\text { "an an an". }\end{array}$ \\
\hline
\end{tabular}

Fonte: Elaborado pelas autoras.

O quadro possibilitou analisar que na maior parte do tempo as habilidades da criança se dão de forma não oral. Percebemos a presença, majoritária, de expressões de sentimentos, imitações, movimentos corporais e expressões faciais utilizadas de modo a estabelecer comunicação com as pessoas envolvidas. Tudo isso fica mais evidente quando Rubi percebia a presença do cão na tela do computador, assim como quando o violão era tocado.

Marinho e Zamo (2017) afirmam que a interação entre o cão e a criança promove o desenvolvimento da afetividade, a expressão de respostas emocionais, aumentando assim a possibilidade de comunicação da criança. Percebemos que ao ser estimulado com o aparecimento da cadela Maya na tela, Rubi respondeu ao estímulo visual direcionando a atenção à tela do computador.

Nogueira et al. (2019, p. 58) explicam que "A presença do cão estimula a expressão da linguagem, seja repetir o latido do cão, saudar e despedir-se”. Foi possível perceber respostas do 
Rubi neste sentido. Estas não vieram de imediato, mas de repetidos estímulos e propostas de ações emitidas pelas pesquisadoras ao longo das sessões.

Na comunicação oral, percebemos a emissão de sons, balbucios e intenções linguísticas ao movimentar os lábios, tentando copiar as pesquisadoras. Estas são consideradas importantes para o desenvolvimento da linguagem, da comunicação e da interação. Deliberato (2017) afirma que, para a criança, quanto mais for submetida a situações dialógicas e com diferentes interlocutores, maior estímulo terá para aquisição da linguagem. Dessa forma, acreditamos que as Intervenções Assistidas por Cães podem, sim, fomentar e proporcionar ambientes que promovam o desenvolvimento linguístico.

Bosa (2006) explica que terapias que estimulem o desenvolvimento das habilidades de comunicação (fala) e interação social são muito relevantes, já que dificuldades nessas áreas podem acompanhar as crianças ao longo da vida. Conclui dizendo que intervenções, como a aqui apresentada, para crianças pequenas com TEA, também são salutares, e que, diante da complexidade do diagnóstico do TEA, quanto mais cedo forem expostas a ambientes ricos em atividades linguísticas, mais cedo podem desenvolver o processo de fala ou outros meios de comunicação. Backes, Bosa e Zanon (2014) defendem a intervenção precoce como fator fundamental, com ganhos significativos para o desenvolvimento linguístico, já que se configura como um dos maiores anseios dos pais/ família em relação aos filhos (a fala).

Por fim, Deliberato (2015) complementa essa ideia dizendo que a fala está como a habilidade mais esperada quando a criança nasce, contudo não é a única forma de comunicação entre as pessoas e pode ser ampliada ou compreendida a partir de outras habilidades como aquelas que mencionamos no Quadro 1. A fala é uma habilidade complexa, necessita que a criança aproprie-se de informações, compartilhe de ideias com intencionalidade e receba diferentes estímulos dialógicos, porém não é a única forma de comunicação. Portanto, ambientes com atividades variadas e as sessões de Intervenção Assistida por Animais mostraram-se importantes na aquisição linguística da criança.

\section{Considerações finais: reflexões iniciais acerca das intervenções assistidas por animais e as habilidades comunicacionais de uma criança com TEA}

A relação homem-animal deixou de ser apenas afetiva, tornou-se terapêutica e passou a exercer diferentes funções, tornando-se objeto de estudo nas áreas da psicologia, saúde e educação. Desde então, as relações de terapias com o uso de animais - denominadas Intervenções Assistidas com Animais (IAA) - sobretudo o cão, vem se consolidando como importantes para o desenvolvimento motor, linguístico, cognitivo de crianças com TEA e/ou outras deficiências.

No Brasil, o uso do cão neste tipo de terapia demonstra ser uma área relativamente nova, nas quais poucas pesquisas são encontradas, em especial, aquelas que apresentam experiências com crianças com TEA e seu potencial para o desenvolvimento linguístico. Acreditamos que as dificuldades em realizar pesquisas nesse contexto são advindas dos rígidos protocolos de segurança e saúde dos animais e do participante envolvido. O cão precisa estar com os protocolos de saúde em dia, ter características e educação canina adequada para as intervenções e estar sempre acompanhado de seu tutor durante as pesquisas. O cão precisa ser treinado por um profissional e ter características específicas para as intervenções, não podendo, por exemplo, ser um cão com características reativas. Assim como o bem-estar do animal precisa ser respeitado.

Nesta pesquisa, ressaltamos que a interação entre o cão e a criança participante não se deu presencialmente devido ao atual momento de pandemia vivenciado no mundo, tal fato pode indicar certo prejuízo, pois a interação presencial envolve toque, carinho e reações do momento que não são possíveis quando mediada pela tecnologia. Foi possível perceber que a conexão da internet pode trazer perdas de expressões linguísticas que poderiam ter sido observadas numa 
relação mais estreita e de contato presencial, mas tal aspecto não invalida as intenções linguísticas registradas. Identificamos momentos de êxitos nas interações propostas e nas intenções linguísticas que Rubi apresentou no episódio analisado, em especial, quando da aparição da cadela Maya na tela do computador.

Outro aspecto importante a ser sinalizado é a participação efetiva da família, fundamental no processo. Contudo, evidenciamos a necessidade de continuar estudando e apontando de que modo e quanto as Intervenções Assistidas por Animais - Cães - com a participação de crianças que não oralizam e com TEA podem mesmo contribuir para o desenvolvimento de intenções linguísticas significativas. Porém, reforçamos que o contexto presencial no qual as interações sociais se dão de forma mais positiva podem ser o local mais adequado.

Por fim, dado o fato de que tomamos a ousadia de qualificar as Intervenções Assistidas por Animais como um serviço de tecnologia assistiva, queremos salientar que nossa intenção foi a de provocar aos pesquisadores de ambas as áreas. Nesse sentido, a provocação tem a expectativa de promover mudanças no cenário nacional, de modo a sinalizar a possibilidade de expandirmos as subáreas da TA para que as IAAs sejam qualificadas como um serviço, dando a visibilidade que elas carecem e a possibilidade de atendimento gratuito em instituições públicas para crianças que dela possam se beneficiar.

\section{Referências}

ANDRÉ, Marli Eliza Dalmazo Afonso. O que é um estudo de caso qualitativo em educação? Revista da FAEEBA Educação e Contemporaneidade. Salvador. v. 22, n. 40, p. 95-103, jul./dez. 2013. Disponível em: https://revistas.uneb. br/index.php/faeeba/article/view/7441/4804. Acesso em: 25 abr. 2020.

ANDRÉ, Marli Eliza Dalmazo Afonso; LUDKE, Menga. Abordagens qualitativas de pesquisa: pesquisa etnográfica e o estudo de caso. In: Pesquisa em Educação: abordagens qualitativas I. Série III. São Paulo: EPU, 1986. p. 11- 45.

ANGELO, Margareth; KAKEHASHI, Tereza Yoshiko; PINHEIRO, Eliana Moreira. O uso de filmagem em pesquisa qualitativa. Revista Latino- americana de enfermagem. Ribeirão Preto, v. 13, p. 717-722, set./out., 2005. Disponível em: https://www.scielo.br/pdf/rlae/v13n5/v13n5a16.pdf. Acesso em: 14 nov. 2020.

AVILA, Lenora. A comunicação e a atuação fonoaudiológica em equoterapia. In: CHELINI, Marie Odile Monier; OTTA, Emma. Terapia Assistida por Animais. São Paulo: Manole, 2016. p. 245-273.

BACKES, Bárbara; BOSA, Cleonice Alves; ZANON, Regina Basso. Identificação dos primeiros sintomas do autismo pelos pais. Revista de Psicologia: teoria e pesquisa. Brasília, DF, v. 30, n. 1, p. 25-30, jan./mar. 2014. Disponível em: http://www.scielo.br/pdf/ptp/v30n1/04.pdf. Acesso em: 06 fev. 2021.

BOSA, Cleonice Alves. Autismo: intervenções psicoeducacionais. Revista Brasileira de Psiquiatria. São Paulo, v. 28, p. 47-53, maio 2006. Disponível em: https://www.scielo.br/pdf/rbp/v28s1/a07v28s1.pdf. Acesso em: 06 fev. 2021.

BRASIL. Constituição da República Federativa do Brasil de 1988. Promulgada em 5 de outubro de 1988. Coordenação de edições técnicas. Brasília, DF, 2016.

BRASIL. Lei no 9.394, de 20 de dezembro de 1996. Estabelece as diretrizes e bases da educação nacional. Brasília, DF. Disponível em: http://www.planalto.gov.br/ccivil_03/Leis/L9394.htm. Acesso em: 09 jan. 2021.

BRASIL. Lei no 12.764 de 27 de dezembro de 2012. Institui a Política Nacional de Proteção dos Direitos da Pessoa com Transtorno do Espectro Autista. Brasília, DF, 2012. Disponível em: http://www.planalto.gov.br/ccivil_03/_ato20112014/2012/lei/L12764.htm. Acesso em: 11 jun. 2020.

BRASIL. Ministério da Educação. Secretaria de Educação Especial. Diretrizes Nacionais para a Educação Especial na Educação Básica. Brasília, DF: MEC/SEESP, 2001. 
BRASIL. Ministério da Educação. Secretaria de Educação Especial. Política Nacional de Educação na Perspectiva da Educação Inclusiva. Brasília, DF, 2008. Disponível em: http://portal.mec.gov.br/index.php?option=com_docman\&vie$\mathrm{w}=$ download\&alias=16690-politica-nacional-de-educacao-especial-na-perspectiva-da-educacao-inclusiva-05122014\&Itemid=30192. Acesso em: 09 fev. 2021.

BRASIL. Subsecretaria Nacional de Promoção dos Direitos da Pessoa com Deficiência. Tecnologia Assistiva. Comitê de Ajudas Técnicas. Brasília, DF: CORDE, 2009.

CAPOTE, Patrícia Sidorenko de Oliveira. Terapia Assistida por Animais (TAA) e deficiência mental: análise do desenvolvimento psicomotor. 2009. Dissertação (Mestrado em Educação) - Universidade Federal de São Carlos, UFSCar, 2009.

CARVALHO, Isis Alves de. Cinoterapia como recurso terapêutico para crianças com Transtorno do Espectro Autista: uma revisão assistemática da literatura. 2014. Monografia (Curso de especialização em psicologia) - Universidade Federal do Rio Grande do Sul, Porto Alegre, 2014.

DELIBERATO, Débora. Questões a respeito da comunicação do aluno com deficiência sem oralidade. In: DELIBERATO, Débora; MANZINI, Eduardo José. (org.). Instrumentos para avaliação de alunos com deficiência sem oralidade. São Carlos: Marquezine e Manzini: ABPEE, 2015. p. 11-21.

DELIBERATO, Débora. Linguagem, interação e comunicação: competências para o desenvolvimento da criança com deficiência não oralizada. In: NUNES, Leila Regina D'Oliveira de Paula; SCHIRMER, Carolina Rizzotto (org.). SALAS ABERTAS: formação de professores e práticas pedagógicas em comunicação alternativa e ampliada nas salas de recurso multifuncionais [online]. Rio de Janeiro, 2017. p. 299-310.

DINIZ, Débora. O que é deficiência? 1. ed. São Paulo: Brasiliense, 2007.

DUARTE, Rosália; EISENBERG, Zena; GARCEZ, Andrea. Produção e análise de videogravações em pesquisas qualitativas. Educação e Pesquisa. São Paulo, v. 37, n. 2, p. 247-262, maio/ ago. 2001. Disponível em: https://www.scielo.br/ pdf/ep/v37n2/v37n2a03.pdf. Acesso em: 09 fev. 2021.

GONÇALVES, Jéssica Oliveira; GOMES, Francielle Gonsalez Correira. Animais que que Curam: a terapia assistida por animais. Revista Uningá, v. 29, n. 1, p. 204 -210, jan., 2017. Disponível em: http://revista.uninga.br/index.php/ uningareviews/article/view/1907. Acesso em: 05 fev. 2021.

HACK, Aline Aparecida Campigotto; SANTOS, Elisiana Paim dos. Cães Terapeutas: a estimulação de crianças com Síndrome de Down. Unoesc \& Ciência - ACHS. Joaçaba, v. 8, n. 2, p. 151-158, dez. 2017. Disponível em: https://pdfs. semanticscholar.org/d942/921fa581b7d9c3deb671118bba65cd95691c.pdf. Acesso em: 16 mar. 2020.

IAHAIO. International Association of Human-animal Interaction Organizations. Las definición de IAHAIO para las intervenciones asistidas con animales involucrados en las intervenciones asistidas con animales. IAHAIO. Estados Unidos da América, 2018. Disponível em: https://iahaio.org/wp/wp-content/uploads/2019/06/iahaio-white-paper-spanish.pdf. Acesso em: 23 fev. 2021.

JANUZZI, Gilberta de Martino. A educação do deficiente no Brasil: dos primórdios ao início do século XXI. 3. ed. Campinas: Autores Associados, 2012.

LOIZOS, Peter. Vídeos, filmes e fotografia como documento de pesquisa. In: BAUER, Martin; GASKELL, George. Pesquisa qualitativa com texto, imagem e som: um manual prático. Petropólis: Vozes. 7. ed., 2008.

MARINHO, Jéssica Riedi Souza; ZAMO, Renata de Souza. Terapia assistida por animais e transtornos do neurodesenvolvimento. Estudos e pesquisas em psicologia. Rio de Janeiro, v. 17, n. 3, p. 1063-1083, 2017.

MANUAL DIAGNÓSTICO E ESTATÍSTICO DE TRANSTORNOS MENTAIS [recurso eletrônico]: DSM-5 / [American Psychiatric Association]. Tradução de Maria Inês Corrêa Nascimento et al. Revisão técnica de Aristides Volpato Cordioli et al. 5. ed. Porto Alegre: Artmed, 2014.

NOGUEIRA, Maria Teresa; NOBRE, Márcia de; RODRIGUEZ, Rita Cássio; BILHALVA, Patrícia. Terapia Assistida por Animais como estratégia pedagógica para crianças que apresentam o transtorno do espectro autista. Revista Gepesvida, v. 05, n. 13, p. 50-60, 2019. Disponível em: http://www.icepsc.com.br/ojs/index.php/gepesvida/article/ view/368. Acesso em: 20 jan. 2021.

PERES, Rodrigo Sanches; SANTOS, Manoel Antônio dos. Considerações gerais e orientações práticas acerca do emprego de estudos de caso na pesquisa científica em Psicologia. Interações, v. 10, n. 20, p. 109-126, jul./dez., 2005. Disponível em: http://pepsic.bvsalud.org/scielo.php?script=sci_arttext\&pid=S1413-29072005000200008. Acesso em: 20 jan. 2021. 
SANT’ANNA, Maria Madalena Moraes (org.). Instrumentos de avaliação do modelo lúdico para crianças com deficiência física (EIP - ACL): manual da versão brasileira adaptada [recurso eletrônico], 2015.

UNESCO. Declaração Mundial sobre Educação para Todos: plano de ação para satisfazer as necessidades básicas de aprendizagem. Tailândia, 1990.

UNESCO. Coordenadoria Nacional para a Integração da Pessoa Portadora de Deficiência (CORDE). Declaração de Salamanca de princípios, política e prática para as necessidades educativas especiais. Brasília, DF: CORDE, 1994.

ZABALZA, Miguel A. Diários de aula: um instrumento de pesquisa e desenvolvimento profissional. Porto Alegre: Artmed, 2004.

Data de submissão: 10/05/2021

Data de aceite: 20/06/2021 